\title{
The Effects of Declining Fertility on Household Socioeconomic Conditions in Tanzania: A Comparative Study of Urban versus Rural Areas of Kwimba District, Mwanza Region
}

\author{
George Felix Masanja, Emmanuel Lwankomezi, and Chrisant Emmanuel \\ Department of Geography, St. Augustine University of Tanzania, P.O. Box 307, Mwanza, Tanzania \\ Correspondence should be addressed to George Felix Masanja; grgmasanja@yahoo.co.uk
}

Received 13 May 2016; Accepted 10 July 2016

Academic Editor: Jonathan Haughton

Copyright (C) 2016 George Felix Masanja et al. This is an open access article distributed under the Creative Commons Attribution License, which permits unrestricted use, distribution, and reproduction in any medium, provided the original work is properly cited.

\begin{abstract}
This study examined the effects of declining fertility on household socioeconomic and health conditions in Tanzania, using a comparative survey of urban versus rural areas of Kwimba District in Mwanza region. Cross-sectional cum causal-comparative research design was adopted for the study. The target population is comprised of all females of the childbearing age residing in Kwimba District. The study utilized a stratified random sampling technique to pick two areas in the district while disproportionate random sampling technique was used to select 196 respondents. A questionnaire was used to elicit information from the respondents. Multivariate analyses were adopted to answer the three research questions of the study. The findings of this study revealed that women of the childbearing age from the two study sites in the district exhibited a small difference regarding fertility inequalities and socioeconomic and health conditions. This study also discovered a significant relationship between critical socioeconomic variables and women's improved socioeconomic status in the communities. These findings, therefore, provide an explanation for the onset of fertility decline which has consequently led to some demonstrated demographic dividend at a household level. The paper recommends enhancement of social transformation and women empowerment in both rural and urban environments for sustained improved living conditions.
\end{abstract}

\section{Introduction}

Current population statistics in Sub-Saharan Africa appear to imply a gradual decline in fertility; see, for example, [16]. The 1991-92 Tanzania Demographic and Health Survey (TDHS), based on a sample of 9,238 women, presented a Total Fertility Rate (TFR) of 6.3 for the years 1989-92 [7]. As reported by the 1996 TDHS, which interviewed 8,120 women, the TFR obtained had decreased to 5.8 for the 199396 period [8]. The 1999 Tanzania Reproductive and Child Health Survey (TRCHS) interviewed a smaller sample of 4,029 women. It reported a TFR for the period from 1996 through 99 of 5.6 [8]. The 2012 census preliminary results present a decline in the level of fertility from 6.5 in 1988 to 5.2 in 2012 [9]. The consistency and harmony indicated by the estimates from these different sources are convincing and satisfactory. It seems fairly clear that there was no decline in
Tanzanian fertility before the early 1980s, but since then there has been a modest decline in Tanzania, especially during the 1990s.

An array of socioeconomic and cultural factors either separately or in combination has been proposed by previous studies to explain patterns of fertility transition; see, for example, $[10,11]$. The major determinants of declining fertility in Tanzania include nuptiality patterns, postponement of first marriage, marital disintegration through divorce or widowhood, and low remarriage rates which are associated with low levels of fertility.

Economic hardship of which many studies have raised in Sub-Saharan countries (see, e.g., $[3,12]$ ) had been fundamental in starting Tanzania's fertility decline. Tanzanians began to experience grave economic problems during the 1970s and early 1980s. It is widely believed that economic hardship resulted in couples seeking to defer or prevent 
further childbearing, especially at parities above three or four (see, e.g., $[12,13])$.

Despite the literature carrying an extensive debate and controversy over the past twenty years on fertility decline, a better understanding of the socio-economic effects and implications on family structures emerging among present African households as a result of such a decline is yet to be fully understood. To our knowledge, few studies have empirically examined the interrelationships between the socio-economic factors, women's autonomy (empowerment) and fertility in Tanzania using field survey data. The specific objectives of this study include examining the observed fertility behaviour among rural versus urban households, determining the socioeconomic and cultural factors contributing to the observed fertility patterns among rural versus urban households, and assessing the observed fertility behaviour patterns in light of demographic dividend or deficit changes among rural versus urban households.

The theoretical framework guiding this study combines three prominent theories advanced to explain the fertility transition in Sub-Saharan Africa. These are the supplydemand framework, innovation-diffusion theory, and wealth flows theory.

(1) Supply-Demand Framework. The supply-demand framework as advanced by [14] extracts its concept mainly from the domain of neoclassical economics. The supply-demand framework suggests that people will eventually realize that lower mortality has produced a situation in which more children are going to survive than can be afforded and, at that point, fertility will decline.

The benefits derived from children which served as a basis for increase in fertility are no longer the case currently. Sustained economic growth over 90 years after the World War II has led to children being increasingly sent to school for education and to health services when sick. The rising cost of education and providing healthcare for children is a major problem for most couples now and has caused a decrease in the demand for children which instead has contributed to a gradual decline in fertility in the African subregion.

(2) Innovation-Diffusion Theory. The most important idea behind the diffusion theory is that social interaction is a major mechanism through which the endorsement of new technologies, ideas, and behaviours takes place. Further, the diffusion theory posits that theories relying on individual rational decision-making in response to economic or structural change could not explain at best the observed fertility transitions in many areas of the world. The outcomes of the two major research efforts completed in the mid-1980s the Princeton European Fertility Project and the World Fertility Survey led certain researchers to conclude that structural and economic changes alone provide an incomplete explanation (see [15-17]).

Connecting this theory to the explanation of fertility transition in Sub-Saharan Africa, it can be deduced that certain lifestyle practices which were characteristic of the developed world have now been diffused into the African culture consequently leading to a decrease in fertility in the African subregion.

(3) Caldwell's Wealth Flows Theory. Caldwell's theory [18, 19] states that the level of fertility is essentially controlled by the direction of the net wealth flows among parents and children, which include all the expected benefits over a lifespan. The end result of this economic justification is either maximum or zero fertility, but this is adjusted by the impact of personal, social, and physiological reasons. The controlling principle underlying the direction of intergenerational wealth flows is the social organization of the society especially family structures. Caldwell argues that in all traditional societies the net wealth flow has been from younger to older generations, which means that economic motives promote high fertility. This flow will only be reversed if the economic and domination of a mental state popularly known as "emotional primacy" is withdrawn from the bond of broader family ties and is focused on the conjugal family. The nucleated family is, therefore, a necessary condition for low fertility and the transition from high to low fertility is a product of social change with economic implications, rather than economic change alone.

From these three theories, it has been noted that contact with western societies influenced the economy, urbanization, migration, education, and even factors such as oppression and inequality of women and hegemony and patriarchy which influence women's position in society in many African societies and cultures. Such a contact has altered the customs and practices, which in turn have led to gradual change infertility behaviour.

\section{Materials and Methods}

2.1. Study Area Characteristics. The study area chosen to examine the research problem is Kwimba District of Mwanza region. Figure 1 presents the map of the district and the study sites. The district lies between latitude $2^{\circ} 59^{\prime}$ to $3^{\circ} 3^{\prime} 43.2^{\prime \prime}$ south of equator and also longitude $33^{\circ} 14^{\prime}$ to $33^{\circ} 21^{\prime} 36^{\prime \prime}$ east of Greenwich. Kwimba District is one of 7 districts of the Mwanza Region of Tanzania. Kwimba's population is 406,509 [20]. The district headquarters is located in Ngudu town centre.

2.2. Study Design. The study applies a cross-sectional and causal-comparative design. It utilizes data gathered from a recent household survey to examine whether economic development and social change might have created supportive conditions in which fertility has modestly declined in Tanzania.

2.3. Population, Sample, and Sampling Procedures. The population for this study comprised all females from Kwimba District whose number amounts to 206,093 [9]. Out of this population, a sampling frame comprising all females of the childbearing age residing in Ngudu urban and Kwimba rural was constructed. Kwimba District had a total of 87,076 females of childbearing age living in 149,725 households [9]. 


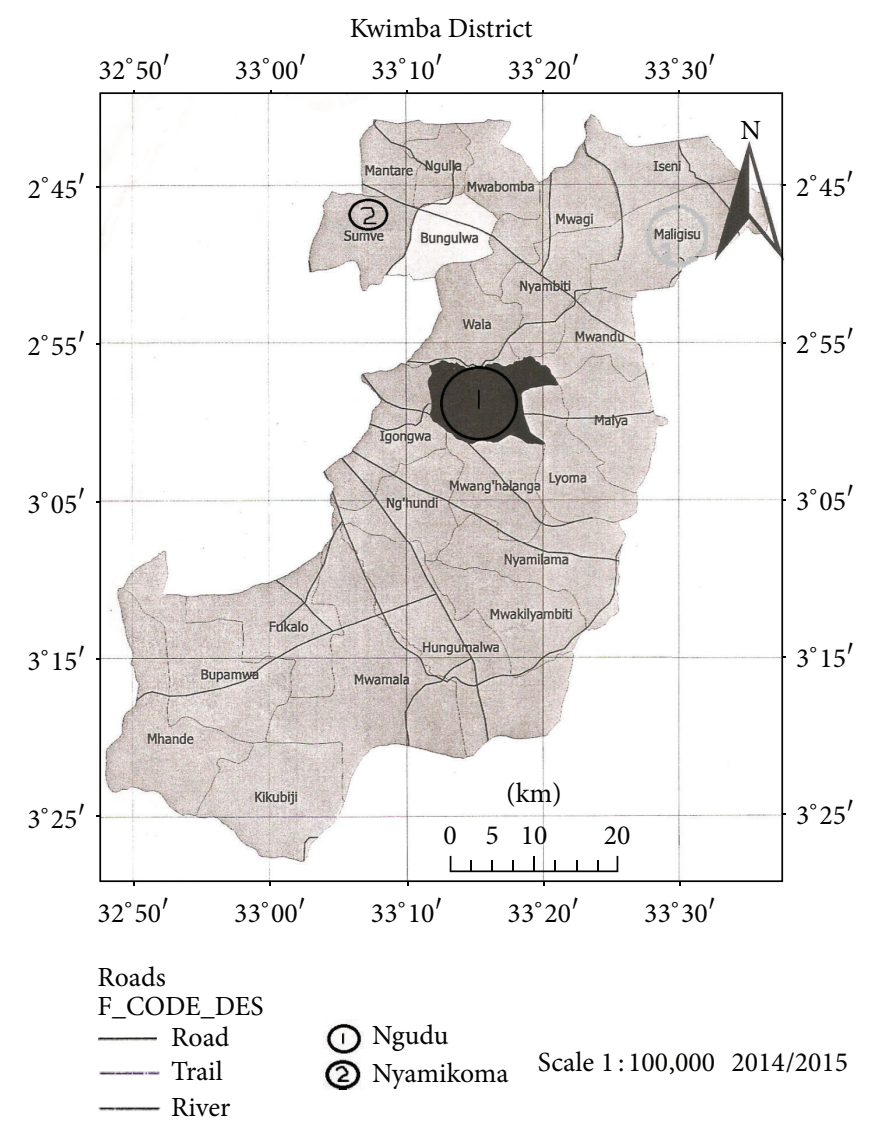

Figure 1: Map of Kwimba District showing study areas. Source: Kwimba Lands office 2015.

From the sampling frame, the sample size was determined by the statistical equation [21]:

$$
n=\frac{z^{2} p q N}{e^{2}(N-1)+z^{2} p q},
$$

where $N$ is population of $87,076, e$ is 0.02 (since the estimate should be within $2 \%$ of true value), and $z$ is 2.005 (as per table of area under normal curve for the given confidence level of 95.5\%); $q=1-p, p=$ taken to be 0.02 based on the result of the pilot study.

The result of the computation was 196.53888 as a sample size. The study adopted a probability sampling design. Seven age groups (15-19 to 45-49) were taken and subjected to disproportionate stratified sampling to obtain sample sizes for the different strata. Results were distributed to study units (households) found in the two selected study sites. The main sample drawn was equally divided into two separate subsamples of 98 respondents each and these represented the two study areas for comparison purposes.

The study sites chosen were Nyamikoma village of Sumve Ward and Ngudu urban centre which is the district seat. The rationale for choosing these sites considered the notable variations in population distribution and environmental conditions both of which formed a basis for varying responses to fertility issues. Specifically, Nyamikoma village was chosen largely on the basis of its remote rural location which was thought to result in relatively low out-migration of mothers. In addition, the area was expected to have relatively high mortality levels due to the general level of underdevelopment. The population of the study area comprises mainly the Sukuma tribe, although some traders and government employees from other tribes have immigrated in small numbers from neighbouring districts and towns to settle. The vast majority of the population makes their living from agriculture on small land holdings, growing maize, cotton, cassava, millet, and rice. The extended family culture is still very strong in rural areas of Kwimba District. Having children, especially many children, is regarded as a source of pride, accomplishment, and future security by young persons. Nevertheless, changes have started to penetrate into this traditional family structure. The younger generations have in some cases started to move out of this arrangement by creating their own economic bases. The disintegration of the traditional family structure gained momentum especially during the last two decades when other means of obtaining land (i.e., through the village government) were made possible. This variation has implications for the labour force and reproductive capacity of the population. A primary consideration in the selection of Ngudu for the study was its urban location which would result in relatively low fertility as expected in urban areas owing to factors suggested by a variety of literatures which includes residents being better educated, secularized, and working in industrial or service sectors. Interviews aimed at trying to understand the magnitude of the difference in fertility transition with respect to place of residence in the district were conducted in Nyamikoma village of Sumve Ward and Ngudu urban centre.

2.4. Data Collection Methods. A complete listing and mapping of all households in each sampled study area were carried out prior to the survey, to stratify households according to the age status of women. A household was deemed eligible for interview if it had a mother whose age fell into the category of 15-49. Detailed socioeconomic and demographic characteristics of 197 women of reproductive age (i.e., 15-49 years) residing in Ngudu and Nyamikoma were collected during the second quarter of 2015 using a structured pretested individual women's questionnaire. This data collection tool was divided into four parts: Part 1 collected individual mothers' information in a household; Part 2 solicited information on factors argued to be responsible for the current declining fertility scenario. Such factors included parity progression, postpartum insusceptibility, modernity, cost of living, women empowerment, and social transformation. Others focused on perceptions of education leading to changes in women's fertility preferences. Part 3 inquired on implications of reduced fertility at a household and individual level. Inquiries concentrated on whether improvements in education empower women in other areas of life, such as participation in decision-making, control of resources, and labour force participation, and whether reduced fertility spurs income growth and increases women's empowerment. Part 4 gathered information on net economic benefits from children, that is, amount provided to children minus amount received by parents. 
2.5. Analytic Framework. Consistent with our study objectives, our analyses examined the effects of an observed falling trend of fertility on household socioeconomic conditions among Tanzanian rural versus urban households based on two major areas of measurement. The first one assessed the observed fertility decline in Kwimba District using predictors. The study identified two main variables: independent and dependent. The independent variables included parity progression, postpartum insusceptibility, the cost of living, social transformation, and women empowerment. The dependent variable (fertility decline) was measured using a bifurcated test of whether a woman had had a bigger number of living children than her reported desired number of children by subtracting her reported desired number from her reported actual number. If the difference was greater than zero, she was coded as having had more children than her stated desired number.

2.5.1. Woman's Parity. We sought to determine whether the impact of norms (modernity versus traditional) differed for women with no children, women with 1-2 children, and women with 3-4 children. Consequently, this variable was stratified into two categories for analysis.

2.5.2. Postpartum Infecundability. The index of postpartum infecundability was used to measure the fertility-inhibiting effect of breastfeeding or postpartum abstinence in the study communities. The paper [22] contends that "in the presence of breastfeeding and postpartum abstinence, the average birth interval equals, approximately, 18.5 months $(7.5+2+9)$ plus the duration of postpartum infecundability, which is defined by length of postpartum amenorrhea and abstinence." The index is calculated as

$$
C_{i}=\frac{20}{18.5}+i
$$

where $i$ is average period of postpartum infecundability (postpartum insusceptibility) produced by breastfeeding and postpartum abstinence.

2.5.3. Social Transformation. This variable is among the socioeconomic and cultural factors contributing to the observed fertility patterns among rural versus urban households. It was measured using two factors, namely, modernity and traditional norms. Modernity norms include the proportions of women desiring a small family size of 3-4 or fewer children and the proportion of women who approved of natural family planning. Modernity's contribution to fertility decline was therefore captured by asking women about their perceptions of how many women in their community used natural family planning. Responses were coded none (1), some (2), most (3), and all (4). Traditional norms on the other hand focused on women's perceptions about age at marriage, education of women, and support for natural family planning. Women were asked whether they believed age at marriage has increased and whether education has changed their mindset on large family sizes and approval of natural family planning. Their responses were coded dichotomously for approval (1) and disapproval (2).
2.5.4. Cost of Living. Respondents were asked whether the cost of living had a fertility-inhibiting effect. Based on the responses, participants were classified as modern women or traditional. Hence, these variables were coded dichotomously as 0 for agreeing and 1 for disagreeing.

2.5.5. Women's Empowerment. This was an independent variable. Measures of women's empowerment are usually used in different contexts to carry multiple meanings. The paper [23] defines women's empowerment as the "ability to make choices." Women were asked whether they ever discussed with their spouses about household decision-making and labour participation. For measuring women's empowerment among rural versus urban mothers, this study employed the Women Empowerment Index (WEI) formula adapted and modified from [24]. Since various decision-making variables are important in a household for different purposes, the study assigned the values as shown in the formula. Each value was rated. A decision-making indicator rated 1-2 indicates low empowerment while 3-4 indicates high empowerment. Therefore, the average scoring value of a particular indicator for all respondents in households of the study area became the average of the value $K . K$ is any rating value of each indicator. The higher the index score, the more empowered the woman.

This study considered four intrahousehold decisionmaking indicators, which are related to the fertility domain. These are

$x_{1}$ : cash management (income, expenditure, and investment for earning),

$x_{2}$ : travel and recreations (mobility to outside home for marketing, visiting relatives, etc.),

$x_{3}$ : children's education (school enrollment, expenditure on books, uniforms, tuitions, etc.),

$x_{4}$ : family planning (freedom for family size preference).

The Women Empowerment Index (WEI) index is calculated as

$$
\mathrm{WEI}(\mathrm{ft})=\frac{\left(\sum_{i=1}^{4} x_{i}\right)}{4},
$$

where WEI (ft) is Women's Empowerment Index for fertility per respondent, $x$ is value of decision-making.

WEI indices are as follows: $1=$ husband alone makes decisions; 2 = husband dominates in decisions; 3 = husband and wife make joint decisions; 4 = wife dominates in decisions; and $5=$ wife alone makes decisions, even in the presence of the husband.

Low and high empowerment scores became the final dichotomous variables that divided respondents who reported having any say in all four household decisions. We performed Ordinary Least Square (OLS) regression to examine the relationship of these two variables.

2.5.6. Demographic Dividend. To measure emerging economic growth that can result from shifts in populations age 
composition, mainly when the proportion of the workingage population (15 to 64 ) is greater than the nonworkingage proportion of the population (14 and younger, and 65 and older), we computed the youth dependency ratio and the children under 15 per household surveyed in Ngudu urban and Nyamikoma rural. These measures would help us see whether many women have now started to enter the labour force and whether this period has led to bearing smaller families and rising income among households in both study areas. It would help us investigate the degree to which the demographic dividend is realized at the household level. Our methodological technique applied logistic regression with interaction terms. Interaction terms were used to examine the cross-sectional relationship between household wealth and age structure in each study area.

Control Variables. They included age, education, residence, and wealth. For assessing nonlinear trends, age in years was squared and used as a predictor. Education was measured as a categorical variable, ranging from "none" to "higher education." Wealth indices were computed based on 9 household assets adapted from the 2010 TDHS. Each household asset was assigned a weight produced through principal component analysis, and the resulting scores were regulated in relation to the standard normal distribution with a mean of 0 and a standard deviation of 1 [25]. The scores were summed for each household and ranking was done. Respondents were divided into quintiles from lowest to highest. All statistical analyses were executed using SPSS Version 16 with significance level set at $p<0.05$.

The second area of measurement required connecting the theoretical framework of the study with observable changes in Kwimba's fertility behaviour. All the three theories of fertility decline apparently converge on economic benefits obtained from children during parents' old age and social interaction factors of which Caldwell's wealth flow theory appears to consider both of them.

The measurement undertaken by this study therefore required testing the relevance and applicability of Caldwell's theory in Kwimba's fertility decline by calculating the net economic benefits from children. It entails calculating the amount provided to children minus amount received by parents in a high fertility society. The measure used to assess the economic contribution of children to their parents is the internal rate of return (IRR). This rate is the discount rate that makes the net present value of investment flows zero. In this study, children are described as an investment by parents who might be motivated to provide old age security. It was decided useful to compare the rate of return of children with other investments. The internal rate of return for a parent's birth cohort was computed using the following formula:

$$
\mathrm{NPV}=\sum_{t=1}^{T} \frac{C_{t}}{(1+r)^{t}}-C_{o}
$$

where $C_{t}$ is net cash inflow during the period $t, C_{o}$ is total initial investment costs, $r$ is discount rate, and $t$ is number of time periods.
Results of Caldwell's theory in Kwimba's fertility decline survey are reported in relation to the emergent life history theory and parental investment advocated by Lawson and Mace.

\section{Results}

3.1. Sociodemographic Characteristics. The majority of respondents $(90.8 \%)$ were between the ages 20 and 34 years with a mean age at marriage 18.87 ( $\mathrm{SD} \pm 2.615)$ years. The mean duration of marriage was 12.96 ( $\mathrm{SD} \pm 8.217$ ). The married respondents were in the majority $(81.7 \%)$. A considerable proportion of the women $(32 \%)$ were married before the age of 16 and $94.5 \%$ were in monogamous relationships. A majority of the women lived in a rural area (85\%). Some $45 \%$ of women reported that they had an occupation. However, only about one out of ten women (12\%) of those who lived in the rural area were engaged in nonagricultural sectors. Fifteen percent had no education while $76 \%$ had a primary or secondary education and $9 \%$ had more than a secondary education. The majority of women (68\%) lived in a household with a low standard of living, the remainder in a household with a medium $(24 \%)$ or high $(8 \%)$ standard of living. On average, women had had 3.8 births (not shown).

The principal resulting variable in this analysis is the fertility level elucidated by the children ever born (CEB) by women before surpassing the age of 50 years. The study population divided into three parity groups-women with no children (weighted $n=29$ ), women with 1-2 children only $(n=100)$, and women with $3-4$ children $(n=67)$-is shown in Table 1.

Results indicate that the sociodemographic characteristics, norms, and behaviours that have contributed to the reduction of fertility varied to some extent among the groups. Not surprisingly, women at higher parity were older. Compared to the other two groups, women with 3-4 children were significantly more likely to have had less education. Crossresidential area distributions across female parity groups indicate that the sample of women was more or less even.

3.2. Differentials in Education. Education was found to be associated with fertility inhibition. Women who had secondary education, primary education, and no formal education, respectively, had 1.16, 1.38, and 1.52 times more children compared to those who had completed higher education. Irrespective of this variation, individual education was not a significant predictor in both communities studied, and its effect was larger in the community than at the individual level. A one standard deviation increase in individual education was associated with an $11 \%$ reduction in fertility (95\% CI $(-0.17,-0.05)$, Wald $Z$-test, $p<0.001)$ when considering the average effect across both communities. Independent of individual background factors, a one standard deviation increase in average education in the community was associated with a $15 \%$ reduction in individual fertility $(95 \%$ CI $(-0.19,-0.08)$, Wald $Z$-test, $p<0.001)$. This result means that a one standard deviation increase in education at the community level, therefore, had 1.2 times larger effect than a comparable 


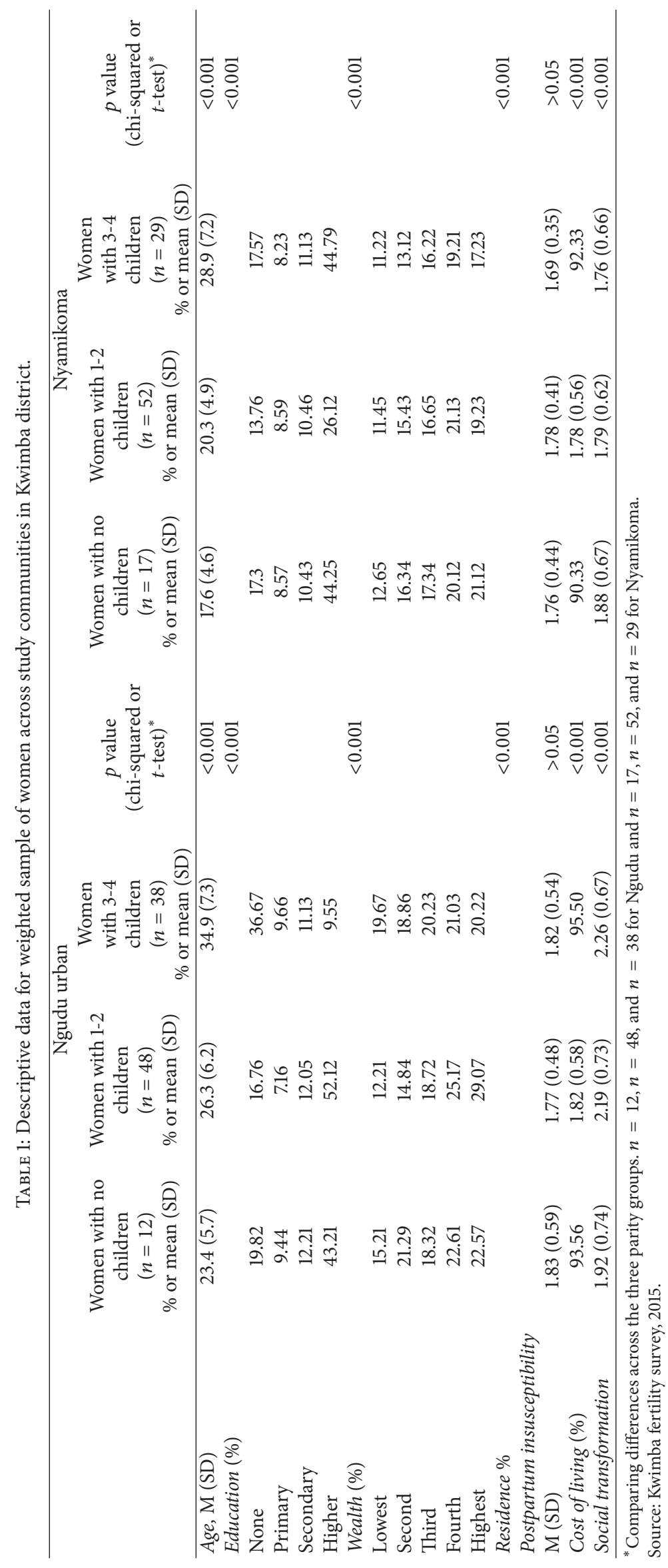


increase at the individual level. This analysis therefore shows that, independent of their own characteristics relative to others, women in the most educated community (apparently in Ngudu urban centre) were predicted to have fewer than a quarter as many children $(1.57 \pm$ s.e. 0.28$)$ as those in the least educated community $(2.16 \pm$ s.e. 0.17$)$.

3.3. Wealth Differentials. The distribution of wealth varied significantly across the three groups, with single-parity women having the greatest wealth. The mean value of an index of wealth was 21.3, with a standard deviation of 14.1. The apportionment of the wealth index was bimodal, with range values falling between 15 and 22. Immense differentials were observed in the wealth index by community residence, education of a woman, and her labour force participation. There were fairly vast differences in the value of the wealth index by age, age-at-first marriage, education, occupation, and parity. The uppermost mean index of wealth was recorded for women in Ngudu urban, and the lowest in Nyamikoma rural. Computed standard deviations showed that the wealth inequality was highest among Nyamikoma rural women. With an increment in a woman's education level, there was an increase in the wealth index: that is, women with postsecondary education had nearly twice the average level of wealth. Women in nonagricultural occupations (mainly found in Ngudu urban) had higher-than-average values for the wealth index while women in agricultural occupations of Nyamikoma are relatively poor. Wealth tends to rise with the age of the woman, the increment being more conspicuous at 25 years and then turning moderate. With the rise in age-atfirst marriage, there was an increase in the index of wealth; that is, women who married at a relatively youthful age were considerably less wealthy than those who married at 25 years or older. Women with parity 1-2 recorded the highest index of wealth. Those with a parity of 3-4 had a noticeably lower mean value for the index of wealth.

3.4. Fertility Differentials. Fertility variations among study areas were obtained utilizing a variety of selected comparison variables such as wealth index, age at marriage, place of residence, education, labour force participation, and social transformation. The percentage of women with children was noticeably lower for women in the wealthiest section (20\%) but differed little among women in the other four quintiles of the distribution of wealth index. Analysis of the current fertility differentials by the value of the wealth index is made more complex by the value differences of the wealth index by other variables that are likely to affect the woman's fertility. Therefore, it was necessary to perform a multivariate analysis, including controls for the effects of confounding variables. Parameter estimates in the logit model are given in Table 3. As to the core finding, the wealth index had a 5 percent significant negative effect on marital fertility. The multiplicative factor showed that a unit increase in the wealth index cut down the odds log of a woman who gave birth in the last 12 months by 0.0036 for Ngudu urban and 0.0033 for Nyamikoma rural.

Analysis by place of residence shows that women living in the rural area had a slightly higher fertility than women living in the urban environment. Computed odds ratios showed that women living in Nyamikoma rural area were 1.14 times more likely $(\mathrm{OR}=1.122)$ to give birth than Ngudu urban women. However, after controlling for other variables, the rural and urban odds ratios were not significant $[p=0.286$ (rural) and $p=0.626$ (urban)]. Table 2 presents the statistics.

Overall, the effect of rural-urban residence has continued to be prominent till the last decade but the results from our survey show that the effect has faded away.

It has been observed during the field study in Nyamikoma rural and Ngudu urban areas data that woman's age at marriage has increased and the proportion married at an early age has fallen substantially in the last two decades. Increase in level of education enhances age at marriage and hence reduces the reproductive span of women and curbs fertility. During the field survey it has been observed that respondents have knowledge on the legal age at marriage in Tanzania. However, the ideal age at marriage in rural areas is still lower than that of urban areas but the gap has narrowed.

Education is the sole factor that has significant effect over time and only those with higher education show distinctly very low fertility. Results from our survey indicate that there is increase in the educational level of women. It is felt that differences between the urban educated and uneducated are not large due to exposure. Moreover, rural educated women are enjoying more autonomy and are taking active part in decision-making which is an indicator of women empowerment.

The analysis of Period Parity Progression Ratios shows that almost all women move for the first child in the district. The proportion of women with progression from first to second child differs with place of residence. The pace of decline is faster among Ngudu urban women with higher parities. In Nyamikoma rural, about a third of women moved from third to fourth child but this occurrence is rare in Ngudu urban.

Contrary to expectation, no significant rural-urban difference in ideal family size is seen in the two study communities in the district especially when influences of other factors are controlled in multivariate analysis. Thus, the observed differences are primarily not net effects.

Zero-order correlations were performed across all variables in both study areas. The main point of examination is to establish the significance of the degree of association among the test variables and to assess overlapping variance. Table 3 presents the zero-order correlation matrix of all the ten test variables. Results show that almost all demographic variables, social transformation, and women empowerment variables were significantly associated with fertility decline. In all but nine cases the magnitude of correlation coefficients is significant at the 0.05 level.

Age also correlates positively with number of children. Surprisingly, the relationship between residence and cost of living is very low and not significant although the result is in the predicted direction. Education correlates inversely with number of children. Nevertheless, the magnitude of correlation coefficient for education and women empowerment is far higher. Residence, however, correlates positively with social transformation but it is also inversely correlated with 


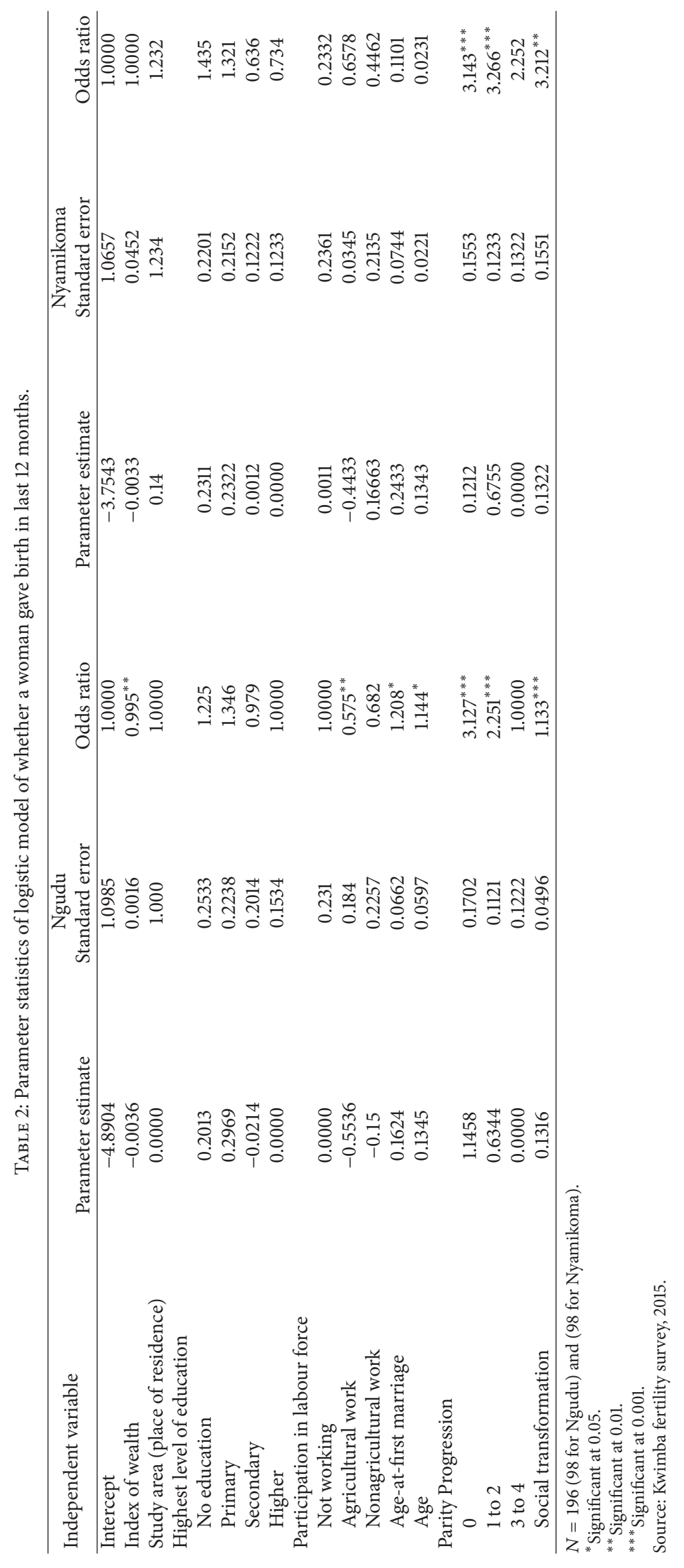


TABLE 3: Zero-order Pearson correlation coefficients matrix for analyzing the relationships between test variables $(N=197)$.

\begin{tabular}{|c|c|c|c|c|c|c|c|c|c|c|}
\hline & $(1)$ & $(2)$ & (3) & $(4)$ & $(5)$ & $(6)$ & $(7)$ & $(8)$ & (9) & $(10)$ \\
\hline Age & 1.00 & $0.16^{* * *}$ & $0.13^{* * *}$ & $-0.13^{*}$ & $-0.04^{*}$ & $-0.47^{* * *}$ & $0.39^{* *}$ & $-0.22^{* *}$ & -0.02 & $0.15^{* *}$ \\
\hline Education & & 1.00 & $0.61^{* * *}$ & $-0.12^{* * *}$ & $11^{* * *}$ & $-0.19^{* * *}$ & $0.03^{* * *}$ & $0.07^{* * *}$ & $0.10^{* * *}$ & $0.31^{*}$ \\
\hline Occupation & & & 1.00 & $0.03^{* * *}$ & $-0.03^{* * *}$ & $-0.07^{* * *}$ & $0.11^{* * *}$ & $0.06^{* * *}$ & $0.11^{* * *}$ & 0.01 \\
\hline Wealth & & & & 1.00 & $0.03^{* * *}$ & $-0.02^{* *}$ & 0.01 & 00 & $0.02^{*}$ & $0.18^{* * *}$ \\
\hline Residence & & & & & 1.00 & $0.26^{* *}$ & $0.02^{* * *}$ & 0.01 & $0.12^{* *}$ & $0.13^{* * *}$ \\
\hline Postpartum insusceptibility & & & & & & 1.00 & $22^{* * *}$ & 0.01 & 0.02 & 0.01 \\
\hline Number of children & & & & & & & 1.00 & $0.06^{* * *}$ & 0.04 & $0.09^{* * *}$ \\
\hline Cost of living & & & & & & & & 1.00 & 0.03 & $0.08^{* * *}$ \\
\hline Social transformation & & & & & & & & & 1.00 & $0.12^{* *}$ \\
\hline Women empowerment & & & & & & & & & & 1.00 \\
\hline
\end{tabular}

${ }^{*} p<0.05,{ }^{* *} p<0.01$, and ${ }^{* * *} p<0.001$.

Source: Kwimba fertility survey, 2015.

number of children. An inverse relationship is observed in settings of economic crisis or personal hardship. Wealth is inversely correlated with number of children (0.01). In both study communities of Kwimba District, the monetization of the economy increases awareness of the costs of raising children regarding food, clothes, health, and education.

3.5. The Effect of Postpartum Insusceptibility. It was necessary to calculate the index of postpartum insusceptibility to determine its influence on fertility reduction. Results indicate that postpartum insusceptibility is the principal inhibitor of fertility in both study communities of Kwimba District. Its role is slightly higher in Ngudu urban (0.47) than in Nyamikoma (0.43). These low indices signal a decreasing fertility trend.

3.6. Cost of Living. The amount of variance in household consumption expenditure explained by the number of children, controlling for other covariates, indicates that, despite the lower coefficient of determination in general, it is statistically significant for both Nyamikoma rural and Ngudu urban households showing that the variables (number of children and equivalent consumption) are well fitted to the Ordinary Least Square regression model. For the Ngudu urban subsample, an additional child leads to an increase of per capita consumption expenditure and adult equivalent consumption expenditure by $9.1 \%$ and $11.5 \%$, respectively, while for the Nyamikoma rural subsample, an additional child leads to an increase of per capita consumption expenditure and adult equivalent consumption expenditure by $7.9 \%$ and $10.2 \%$, respectively, on average. Percentages also show that the overall consumption expenditure is higher for urban relative to rural households.

In connection with this finding, most of the respondents in Ngudu urban and among Nyamikoma rural young women cited economic factor as the main reason to choose a small family size. They mentioned the high cost of child rearing. Older urban women also mentioned that high living costs in urban areas motivated them to have a small family. Women mentioned that educational cost of children has increased and increased number of educated youth in the job market required quality education which is expensive. Therefore, quality of children became more important to parents instead of quantity of children.

3.7. Social Transformation. To determine whether modernity values (proportion of women desiring a small family size and the proportion of women who approve family planning) intervened between background characteristics and family planning adoption, first-order partial correlations were computed. In each case, the effect of a particular modernity value was held constant when determining the relationship between background characteristics and adoption. Results indicate that, in most cases, the value of the partial correlation was substantially reduced thereby providing evidence that the particular modernity values in question did have an intervening role. For example, the proportion of women desiring a small family size correlated positively and significantly $(r=0.23, p<0.001 ; r=19, p<0.001)$ with family planning adoption for Ngudu urban and Nyamikoma rural, respectively.

As regards traditional norms, correlation coefficients between women's perceptions about age at marriage and family planning adoption controlling for place of residence, wealth, and education produced values of 0.14 and 0.12 at $p<$ 0.01 for Ngudu urban and Nyamikoma rural. Education and family planning adoption had values of 0.24 and 0.21 at $p<$ 0.01 for Ngudu urban and Nyamikoma rural. The coefficients indicate that mother's education and family adoption is in a positive direction.

Correlation between age at marriage and adoption of family planning had coefficient values of 0.4 and 0.2 at $p<0.01$ when holding place of residence, wealth, and education constant. Such a finding shows that age at marriage and adoption of family planning is negatively correlated suggesting that young mothers are quicker at approving family planning as opposed to older mothers.

3.8. Women Empowerment. An examination of the effects of women's empowerment on the ideal number of children was performed after controlling for background variables. An Ordinary Least Squared (OLS) regression helped to interpret 
TABLE 4: Summary of the effects of control variables on the ideal number of children and women's empowerment.

\begin{tabular}{lcc}
\hline & Ngudu (high) & Nyamikoma (low) \\
\hline Age & $-(* *)$ & $+(*)$ \\
Residence & $-(* *)$ & $-(*)$ \\
CEB & $+(* *)$ & $+(* *)$ \\
Age $*$ CEB & $-(* *)$ & $+(*)$ \\
$\begin{array}{l}\text { Husband's education } \\
\text { Husband's occupation } \\
\text { (agriculture) }\end{array}$ & - & - \\
Labour force participation & - & - \\
\hline $\begin{array}{l}\text { Factors } \\
\quad \text { Education factor }\end{array}$ & + & $+(* *)$ \\
$\quad \begin{array}{l}\text { Household decision-making } \\
\text { factor }\end{array}$ & $-(* *)$ & $-(* *)$ \\
\hline
\end{tabular}

$*$ : significant at $p$ value $<0.05$.

$* *$ : significant at $p$ value $<0.01$.

OLS regression model.

Source: Kwimba fertility survey, 2015.

results which give initial impressions on how the variables behave. The controlled variables were set at women's age, residence, the number of children ever born, and husband's socioeconomic and demographic characteristics.

Table 4 indicates that most of the control variables of the women's demographic characteristics are statistically significant across both study areas. It is worth taking into account the husband's characteristics while exploring the ideal number of children since the decision about children is usually a joint decision. Interestingly, husbands' background characteristics do not seem to be influential in fertility preference. The effect of control variables on the types of husband's occupation is not consistent across the two study areas, and husband's education has absolutely no significant effect on any study community. The results have consistently found three factors including women's labour force participation, women's education, and women's household decision-making that affect individual women's empowerment. Woman's engagement in paid employment (mostly found in Ngudu urban centre) was found to increase the odds of favouring the ideal number of children by $6.2 \%$ relative to Nyamikoma by $4.8 \%$. The emerging result is that labour force participation factor is statistically associated with a lower ideal number of children.

The correlation between household decision-making factor and the ideal number of children is negatively significant in Ngudu and Nyamikoma, which shows that women in the category of higher level of household decision-making prefer smaller ideal numbers of children.

\subsection{Demographic Dividend}

3.9.1. Cross-Sectional Relationship between Household Wealth and Age Structure. Table 5 displays the results of this estimation in our sample. We show two main specifications. In columns 1 and 3, we take youth dependency ratio, defined as the number of children under the age of 15 per adult of working age in the household being a dependent variable, and regress it on the wealth quintiles. In columns 2 and 4, we repeat the regressions from columns 1 and 3 but use the number of children under 15 as a dependent variable.

According to the results, the estimated coefficients in columns 1 and 3 imply that the wealthiest Ngudu urban households have on average a 0.265 lower dependency ratio, and support on average 0.47 children less than the poorest households while for Nyamikoma rural, the corresponding values are 0.158 against 0.270 .

Results displayed in columns 2 and 4 suggest that the decline in the number of dependent children was 0.01 among households in the lowest quintile; 0.03 in the second quintile; 0.07 in the third quintile; 0.15 in the fourth; and 0.47 in the top wealth quintile for Ngudu urban. Values for Nyamikoma rural were $0.02,0.03,0.03,0.17$, and 0.27 , respectively. These results appear to suggest that the poor in Kwimba might have started the process of transition, trying to catch up with the rich. This modest change for them accrues from the reduction of their family sizes from five to four compared to the four to three or even lower reduction by the rich.

The testing of Caldwell's wealth flow transfer to assess its applicability in Kwimba District demanded to compute the average economic costs paid by a parent and the economic benefits received by a parent. Benefits of children are the net transfers received by parents during old age. Net transfers received by a parent were measured relative to consumption of the parent. These costs and benefits were analyzed over the lifecycle of a parent by tracking their birth cohorts. The study provides results which show that the net familial transfers of the average parent over the entire parental lifecycle are such that parents of high cohort fertility (3-4 children) receive positive net familial transfers from children. The rate of return from investment in children ranged from 5 to 6 percent. The average rate of return from investment by parents of low cohort fertility ( $<3$ children) ranged from 3 to 4 percent. An interesting observation is that despite parents of low cohort fertility also receiving net familial transfers from children, the data trend indicates that children are net economic costs to young parents with fewer children as opposed to the old with many children in the current period of time.

\section{Discussion}

Findings of this comparative study suggest that both study areas have indicated a modest fertility decline despite Ngudu urban having a higher rate of decline compared to Nyamikoma rural. Results also indicate that all three women's empowerment factors show significant effects on women's fertility measured by the ideal number of children. Background characteristics such as age, urban residence, religion, and the current number of children ever born of the women have significant effects on her fertility preference. Household decision-making and labour force participation have demonstrated to be associated with lower fertility preference in both communities. These results conform to the findings of [26].

Results from field study have also shown that older rural women want to have one additional child compared to their 
TABLE 5: Ordinary Least Square (OLS) regression results for household wealth and age structure. Estimated coefficients.

\begin{tabular}{|c|c|c|c|c|}
\hline Dependent variable & $\begin{array}{c}\text { Youth dependency } \\
\text { ratio } \\
\text { (Ngudu urban) } \\
\text { (1) }\end{array}$ & $\begin{array}{l}\text { Children under } 15 \\
\text { per household } \\
\text { (Ngudu urban) } \\
\text { (2) }\end{array}$ & $\begin{array}{c}\text { Youth dependency ratio } \\
\text { (Nyamikoma rural) } \\
\text { (3) }\end{array}$ & $\begin{array}{l}\text { Children under } 15 \text { per } \\
\text { household } \\
\text { (Nyamikoma rural) } \\
(4)\end{array}$ \\
\hline First quintile (lowest) & $\begin{array}{c}-0.101^{*} \\
(0.475)\end{array}$ & $\begin{array}{l}-0.0117 \\
(0.0261)\end{array}$ & $\begin{array}{c}-0.0009 \\
(0.143)\end{array}$ & $\begin{array}{c}0.0221 \\
(0.03422)\end{array}$ \\
\hline Second quintile & $\begin{array}{l}-0.114^{*} \\
(0.0570)\end{array}$ & $\begin{array}{l}-0.0250 \\
(0.0203)\end{array}$ & $\begin{array}{c}-0.00154 \\
(0.156)\end{array}$ & $\begin{array}{c}0.0305 \\
(0.0568)\end{array}$ \\
\hline Third quintile & $\begin{array}{r}-0.126^{* * *} \\
(0.0305)\end{array}$ & $\begin{array}{c}-0.0684^{* * *} \\
(0.0230)\end{array}$ & $\begin{array}{r}-0.205^{* *} \\
(0.0800)\end{array}$ & $\begin{array}{l}-0.0318 \\
(0.0584)\end{array}$ \\
\hline Fourth quintile & $\begin{array}{c}-0.266^{* * *} \\
(0.0396)\end{array}$ & $\begin{array}{c}-0.149^{* * *} \\
(0.0211)\end{array}$ & $\begin{array}{c}-0.382^{* * *} \\
(0.114)\end{array}$ & $\begin{array}{r}-0.171^{* * *} \\
(0.0463)\end{array}$ \\
\hline Fifth quintile (wealthiest) & $\begin{array}{c}-0.265^{* * *} \\
(0.0334)\end{array}$ & $\begin{array}{c}-0.470^{* * *} \\
(0.0299)\end{array}$ & $\begin{array}{c}-0.158^{* * *} \\
(0.0996)\end{array}$ & $\begin{array}{c}-0.270^{* * *} \\
(0.0609)\end{array}$ \\
\hline$p$-value & 0.00 & 0.00 & 0.13 & 0.00 \\
\hline
\end{tabular}

Robust standard errors in parentheses.

${ }^{* * *} p<0.01,{ }^{* *} p<0.05$, and ${ }^{*} p<0.1$.

Source: Kwimba fertility survey, 2015.

urban counterparts and the trend remained the same in recent years. Moreover, older women in rural areas desired to have a larger family and in contrast their knowledge on fertility regulation has been found to be low. Young rural women on the other hand prefer to have at least two children and also aspire to provide quality education to their children.

The desire for fewer children in Kwimba District might be a consequence of emerging population pressure on the cultivable land and a lack of labour opportunities outside agriculture, which negate any current or future benefits from children's work. Instead, children are seen as a burden in terms of extra mouths to feed, extra outlay on school fees, clothes, and healthcare. These findings confirm the assumption that desired fertility is the outcome of parents' assessment of the costs and benefits of their offspring. Such results conform to conclusions of [14].

Drawing from the impact of household wealth on fertility, results have shown a notice able gap in fertility rates between women in the highest wealth quintile and the lowest quintile. While the lowest quintiles in both communities have youth dependency ratios of one or higher, the highest quintiles range between 0.6 (Ngudu urban) and 0.75 (Nyamikoma rural). The national youth dependency ratio stands at 0.84 [27]. Our results are consistent with a small but growing body of the literature that asserts fertility and family resources are negatively linked. See, for example, [28].

As regards social transformation, the results strongly suggest that transmission of norms and attitudes from highly (Ngudu urban centre) to less educated women (Nyamikoma) increases the pace of fertility decline, the moment a critical mass of educated women is reached as has happened in Nyamikoma. The principal mechanism driving this effect appears to be an increased frequency of interaction among the two communities. This exposure may change the expectations that less educated women have about the most appropriate behaviour in their local community while also legitimizing their reproductive preferences within their private social networks. This can then contribute to a faster fertility decline in the community.

With respect to Caldwell's wealth transfer theory, findings have shown that both rates of return from parents' deposits and children are declining. Rates of return from children are dropping faster than the parents' deposits. Physical investments are turning out to be more promising than investment in children. If parents take into account the prevailing financial opportunity costs, economic returns of children are still positive for the elderly parents. The returns are negative, however, for the young parents since the returns from children are slowly declining.

The new theory about rising investment costs of rearing socially and economically competitive offspring has triggered a debate and has been supported by advocates of parental investment and the optimisation of human family size. The proponents of this life history theory and human reproductive behaviour view fertility limitation through a reallocation of resources to parental investment which ultimately can represent an adaptive strategy to ensure offspring success [20,26, 29-34]. They further believe that a trade-off between quantity and "quality" of offspring is fundamental to human life history. Additionally, this investment-related model identifies education as a primary attribute involved in the increase in personal or parental investment in modern economies [35].

Kaplan and Lancaster [29] and Kaplan et al. [30] who extended the life history theory and the economics of the family to explain how quality-quantity trade-off leads to low fertility behaviour stated that a fertility decline in a given society begins when parents perceive the benefits and costs of child schooling. Their main argument is that modernization serves to escalate relationships between parental investment and children's success, eliciting evolved mechanisms of fertility regulation to value offspring quality over quantity. Following this stance, they assert that a decline in fertility may also be construed as a strategic move from high fertility to high investment in fewer offspring. 
While this argument provides another explanation for fertility decline, it should be noted that this phenomenon is not of developed countries alone where rewards to fertility limitation fall selectively on relatively wealthy individuals. Lawson and Mace [20] who have studied at length on contemporary British families demonstrate that offspring with an investing mother tend to have an investing father as well, leading to a visible range of measures of child health and educational success. This finding indicates that richer women are likely to have lower fertility than poorer households. Such a result is in line with fertility models that speculate this negative relationship arguing that families with higher income and status tend to substitute quantity of children with quality [36-38]. This shift in focus from having many children to increased consciousness about their "quality" could be one way to explain the inverse relationship between wealth status and fertility.

In developing countries, fertility limitation resulting from quality-quantity trade-offs has also been evident. The result of the study by [16] shows that exogenous increase in fertility decreases child quality and suggests that a decrease in family size brought about by exogenous factors increases the quality of children. Li et al. [27] also find supporting evidence to the quality-quantity trade-off by examining the effect of family size on child educational achievement in China. Using educational achievement and school achievement as a measure of child quality the study finds a negative correlation between family size and child quality providing an empirical support to the quality-quantity model of fertility.

Turning back to the findings of this study, the structural change in socioeconomic conditions in the Tanzania and Kwimba District in particular has for the past two decades helped to make the difference between them smaller and motivate rural women to adopt small family. The diffusion of ideas of small family and change in aspirations about children from urban to rural area has contributed to a modest decline in rural fertility rate. Alongside with this scenario, the fall in the number of children in African families frees capital available to elevate child quality. For example, the intangible economic activities that children provide to their parents may be defined as the product of the number of children and their average quality $[16,39]$.

Further investigation on this fertility change has revealed that parents in the two study areas are highly concerned about the schooling of their children owing to the internal efficiency of the educational system in the city being quite low. Though education is free at primary and secondary levels in Tanzania, some amount of parents' money is occasionally paid for school uniform, textbook services, extra curricula activities, and the like. This situation holds true in Kwimba District, and this study suggests that economic crisis is in a position to bring about fertility decline through time by changing the behaviour of the young generation who is partly survivors of the current economic squeeze.

\section{Conclusions}

The onset of the fertility transition in Kwimba District has been demonstrated by the tested data of this study.
Similarly, initial signals of the demographic dividend at a local scale have also started to emerge. The available crossstudy areas' evidence suggests that the decline in fertility triggered during the demographic transition is associated with lower dependency ratios, increased education, and increased women empowerment. The associations between income and dependency ratios have on average directed this study to conclude that households with higher incomes in Kwimba District have fewer children to support.

Despite the strong association between wealth and age structure at the household level, the implications of the demographic transition on inequalities between the urban and rural women in Kwimba District have not been obvious from a perspective characterized by continuous change. This is because the benefits of the demographic transition in terms of lower dependency ratios accrued almost to all socioeconomic groups though at a different scale.

Although children in Africa are still net economic benefits in high fertility cohorts, they are at the same time turning out to be net economic costs in low fertility cohorts. Results of the Kwimba study conclude that the internal rate of return of children decreases over a parent's birth cohort such that a falling trend is observed for parents who have low cohort fertility ( $<3$ children). Additionally, results for the Ngudu and Nyamikoma study confirm the theoretical prediction that having a higher number of children has an adverse effect on the consumption expenditure of a given household.

Drawing from the analysis emanating from the data presented, the findings of this study are consistent with those of many nonevolutionary studies on the demographic transition. However, data analysis of this study also indicates that smaller numbers of surviving children per woman are also related to increased investment in mothers and their children (measured here by formal education) and therefore underlines the potential relevance of a combination of models in bringing about fertility transition.

Based on the findings, this study therefore recommends policies and programmes targeted at regulating high fertility to continue suppressing entrenched patriarchal values and gender inequalities which fuel stalling of fertility decline in Tanzania and many parts of Sub-Saharan Africa.

\section{Competing Interests}

The authors declare that they have no competing interests.

\section{Authors' Contributions}

George Felix Masanja is the major contributor in this paper.

\section{Acknowledgments}

The authors would like to thank St. Augustine University of Tanzania for the financial support to this study.

\section{References}

[1] E. Van de Walle and D. Meekers, "Marriage drinks and Kola nuts," in Nuptiality in Sub-Saharan Africa: Contemporary 
Anthropological and Demographic Perspectives, C. Bledsole and G. Pison, Eds., pp. 57-73, Clarendon Press, Oxford, UK, 1994.

[2] A. Hinde and A. J. Mturi, "Recent trends in Tanzanian fertility," Population Studies, vol. 54, no. 2, pp. 177-191, 2000.

[3] A. Mturi and A. Hinde, Fertility levels and differentials in Tanzania, Population Division Department of Economic and Social Affairs, UN/POP/PFD/2001/8, http://www.un.org/esa/ population/publications/prospectsdecline/mturi.pdf.

[4] P. Makinwa-Adebusoye, Socio-Cultural Factors Affecting Fertility in Sub-Saharan Africa, The Nigerian Institute of Social and Economic Research (NISER), Lagos, Nigeria, 2001, http://www .un.org/esa/population/publications/prospectsdecline/makinwa.pdf.

[5] B. Malmberg, "Demography and the development potential of sub-Saharan Africa," Current African Issues 38, 2008, http:// mercury.ethz.ch/serviceengine/Files/ISN/92313/ipublicationdocument_singledocument/33e93ac7-4383-4cb3-aa0f81471311e250/en/38.pdf.

[6] A. Agwanda and A. Amani, "Population Growth, Structure, and Momentum in Tanzania," Dicussion Paper, Economic and Social Research Foundation, Dar es Salaam, Tanzania, 2014, http://www.thdr.or.tz/docs/THDR-BP-7.pdf.

[7] S. Ngallaba, S. H. Kapiga, I. Ruyobya, and J. T. Boerma, Tanzania Demographic and Health Survey: 1991/1992, Bureau of Statistics, Dar es Salaam, Tanzania; Macro International, Calverton, Md, USA, 1993.

[8] National Bureau of Statistics and Macro International Inc, Tanzania Demographic and Health Survey: 1996, Bureau of Statistics and Calverton, Dar es Salaam, Tanzania; Macro International Inc. National Bureau of Statistics. National Bureau of Statistics and Macro International Inc, Maryland, Md, USA, 2000.

[9] National Bureau of Statistics (NBS), Office of Chief Government Statistician (OCGS), and Zanzibar, The 2012 Population and Housing Census: Basic Demographic and Socio-Economic Profile; Key Findings, NBS and OCGS, Dar es Salaam, Tanzania, 2014.

[10] S. Madhavan, "Female relationships and demographic outcomes in sub-Saharan Africa," Sociological Forum, vol. 16, no. 3, pp. 503-527, 2001.

[11] B. Bigombe and G. M. Khadiagala, "Major Trends Affecting Families in Sub-Saharan Africa," Major Trends Affecting Families: A Background Document, Report for United Nations, Department of Economic and Social Affairs, Division for Social Policy and Development, Program on the Family, 2003, http:// www.un.org/esa/socdev/family/Publications/mtbigombe.pdf.

[12] N. Rutenberg and I. Diamond, "Fertility in botswana: the recent decline and future prospects," Demography, vol. 30, no. 2, pp. 143-157, 1993.

[13] J. Schaller, "For richer, if not for poorer? Marriage and divorce over the business cycle," Journal of Population Economics, vol. 26, no. 3, pp. 1007-1033, 2013.

[14] R. A. Easterline and E. N. Crimmins, The Fertility Revolution: A Demand-Supply Analysis, University of Chicago Press, Chicago, Ill, USA, 1985.

[15] J. Cleland and C. Wilson, "Demand theories of the fertility transition: an iconoclastic view," Population Studies, vol. 41, no. 1, pp. 5-30, 1987.

[16] A. Cigno and F. C. Rosati, "Why do Indian children work, and is it bad for them?" Discussion Paper 115, IZA, Bonn, Germany, 2000 .
[17] J. Bongaarts and S. C. Watkins, "Social interactions and contemporary fertility transitions," Population and Development Review, vol. 22, no. 4, pp. 639-682, 1996.

[18] J. C. Caldwell, "Toward a restatement of demographic transition theory," Population and Development Review, vol. 2, no. 3-4, pp. 321-366, 1976.

[19] J. C. Cadwell, Theory of Fertility Decline, Academic Press, New York, NY, USA, 1982.

[20] D. W. Lawson and R. Mace, "Parental investment and the optimization of human family size," Philosophical Transactions of the Royal Society B: Biological Sciences, vol. 366, no. 1563, pp. 333-343, 2011.

[21] C. R. Kothari, Research Methodology: Methods and Techniques, Wishwa Prakashan, New Delhi, India, 2003.

[22] J. Bongaarts and E. G. Potter, Fertility, Biology, and Behavior: An Analysis of the Proximate Determinants, Academic Press, New York, NY, USA, 1983.

[23] N. Kabeer, "The conditions and consequences of choices: reflections on the measurement of women's empowerment," UNRISD Discussion Paper 108, United Nations Research Institute for Social Development (UNRISD), Geneva, Switzerland, 1999, http://www.unrisd.org/80256B3C005BCCF9/(httpAuxPages)/31EEF181BEC398A380256B67005B720A/ \$file/dp108.pdf.

[24] M. L. Bose, A. Ahmad, and M. Hossain, "The role of gender in economic activities with special reference to women's participation and empowerment in rural Bangladesh," Gender, Technology and Development, vol. 13, no. 1, pp. 69-102, 2009.

[25] D. Gwatkin, S. Rutstein, K. Johnson, R. Pande, and A. Wagstaff, Socio-Economic Differences in Health, Nutrition, and Population, World Bank, Washington, DC, USA, 2000, http:// siteresources.worldbank.org/INTPAH/Resources/IndicatorsOverview.pdf.

[26] H. Kaplan, "A theory of fertility and parental investment in traditional and modern human societies," Yearbook of Physical Anthropology, vol. 39, pp. 91-135, 1996.

[27] H. Li, J. Zhang, and Y. Zhu, "The quantity-quality tradeoff of children in a developing country: identification using chinese twins," Demography, vol. 45, no. 1, pp. 223-243, 2008 http://www.ncbi.nlm.nih.gov/pmc/articles/PMC2831373/.

[28] D. E. Bloom, D. Canning, G. Fink, and J. E. Finlay, "Fertility, female labor force participation, and the demographic dividend," Journal of Economic Growth, vol. 14, no. 2, pp. 79-101, 2009.

[29] H. Kaplan and J. Lancaster, "The evolutionary economics and psychology of the demographic transition to low fertility," in Adaptation and Human Behavior: An Anthropological Perspective, L. Cronk, N. Chagnon, and W. Irons, Eds., pp. 283-322, Aldine de Gruyter, Hawthorne, NY, USA, 2000.

[30] H. Kaplan, J. B. Lancaster, W. T. Tucker, and K. G. Anderson, "Evolutionary approach to below replacement fertility," American Journal of Human Biology, vol. 14, no. 2, pp. 233-256, 2002.

[31] D. W. Lawson and R. Mace, "Sibling configuration and childhood growth in contemporary British families," International Journal of Epidemiology, vol. 37, no. 6, pp. 1408-1421, 2008.

[32] D. W. Lawson and R. Mace, "Trade-offs in modern parenting: a longitudinal study of sibling competition for parental care," Evolution and Human Behavior, vol. 30, no. 3, pp. 170-183, 2009.

[33] D. W. Lawson and R. Mace, "Optimizing modern family size: trade-offs between fertility and the economic costs of reproduction," Human Nature, vol. 21, no. 1, pp. 39-61, 2010. 
[34] R. Mace, "The evolutionary ecology of human family size," in The Oxford Handbook of Evolutionary Psychology, R. I. M. Dunbar and L. Barrett, Eds., pp. 383-396, Oxford University Press, Oxford, UK, 2007.

[35] B. S. Low, C. P. Simon, and K. G. Anderson, "An evolutionary ecological perspective on demographic transitions: modeling multiple currencies," American Journal of Human Biology, vol. 14, no. 2, pp. 149-167, 2002.

[36] R. J. Quinlan, "Gender and risk in a matrifocal Caribbean community: a view from behavioral ecology," American Anthropologist, vol. 108, no. 3, pp. 464-479, 2006.

[37] R. J. Quinlan, "Human parental effort and environmental risk," Proceedings of the Royal Society B: Biological Sciences, vol. 274, no. 1606, pp. 121-125, 2007.

[38] R. J. Quinlan and M. B. Quinlan, "Parenting and cultures of risk: a comparative analysis of infidelity, aggression, \& witchcraft," American Anthropologist, vol. 109, no. 1, pp. 164-179, 2007.

[39] F. Tadese, Socio-economic determinants of fertility in urban Ethiopia [M.S. thesis], School of Graduate Studies of Addis Ababa University, Addis Ababa, Ethiopia, 2008. 


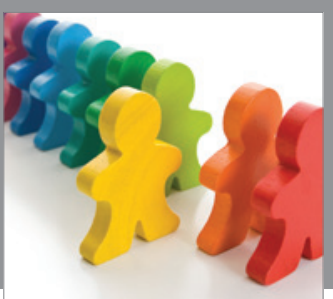

Autism

Research and Treatment
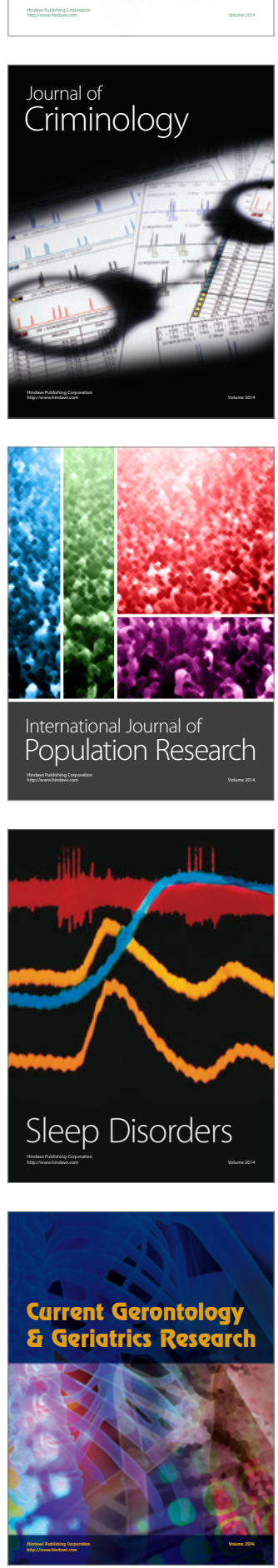

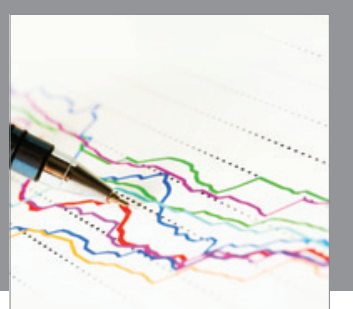

Economics

Research International
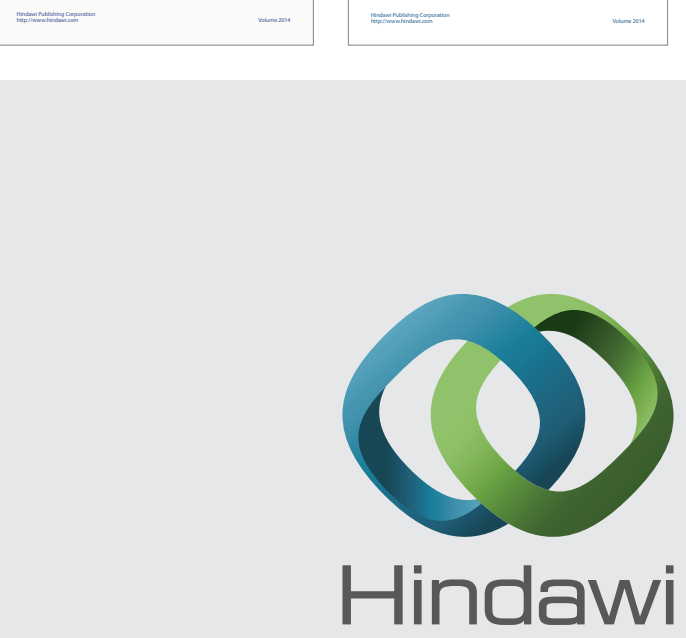

Submit your manuscripts at

http://www.hindawi.com
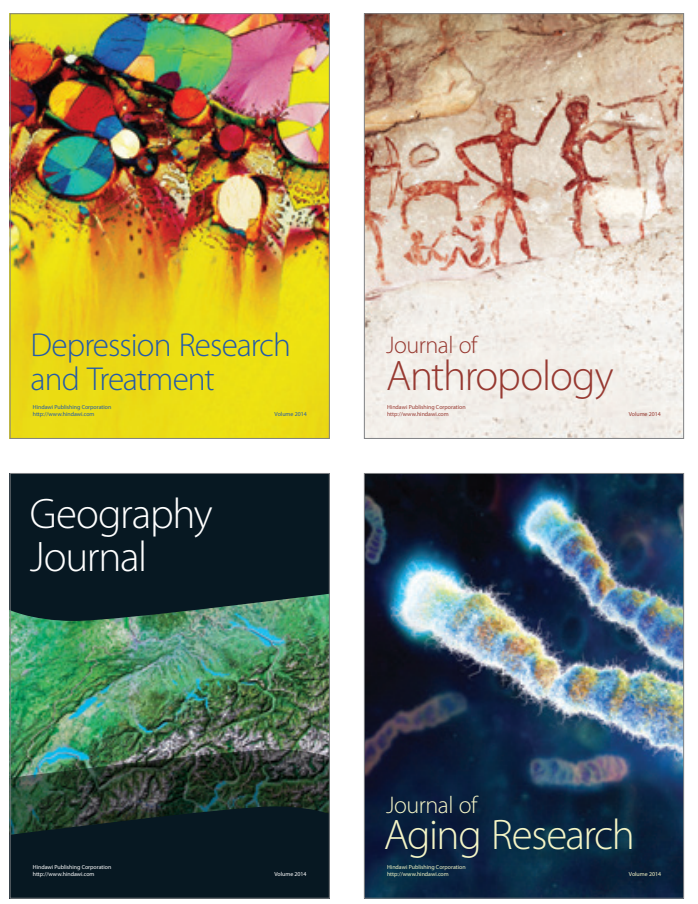
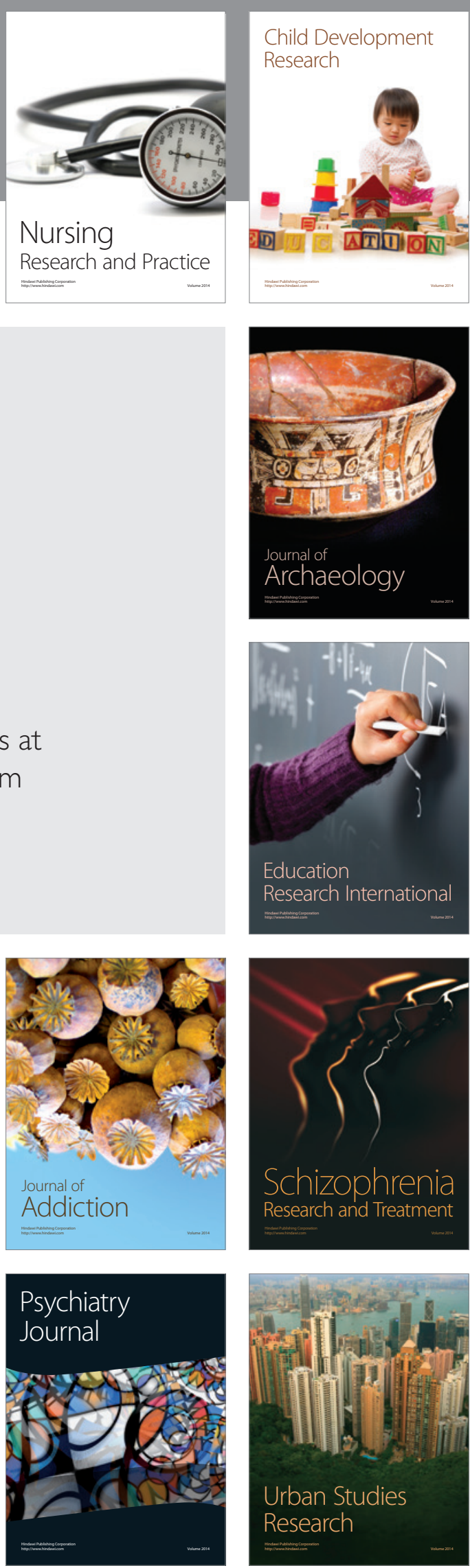